\title{
Relationship Between Fungicide Sensitivity and Control of Gummy Stem Blight of Watermelon Under Field Conditions
}

A. Thomas, D. B. Langston, Jr., H. F. Sanders, and K. L. Stevenson, Department of Plant Pathology, University of Georgia, Tifton, 31793 \begin{abstract}
blight of watermelon under field conditions. Plant Dis. 96:1780-1784.
Gummy stem blight (GSB), caused by the fungus Didymella bryoniae, is the most destructive disease of watermelon and is managed primarily with fungicides. $D$. bryoniae has developed resistance to many fungicides that were once very effective, including azoxystrobin, boscalid, and thiophanate-methyl. Field experiments were conducted in Tifton (TN) and Reidsville (RV), GA in 2009 and 2010 to establish a relationship between frequency of resistance to a fungicide based on in vitro assays and its efficacy in the management of GSB. Frequency of resistance to boscalid, thiophanate-methyl, and azoxystrobin was $>0.80$ in isolates collected from nontreated plots in both locations and years. All isolates collected after six applications of boscalid, thiophanatemethyl, or azoxystrobin were resistant to the respective fungicide. All isolates collected from treated and nontreated plots were sensitive to
\end{abstract}

Abstract

Thomas, A., Langston, D. B., Jr., Sanders, H. F., and Stevenson, K. L. 2012. Relationship between fungicide sensitivity and control of gummy stem

tebuconazole and difenoconazole. GSB severity was assessed on a weekly basis from 63 days after planting. GSB severity in plots treated with boscalid, thiophanate-methyl, or azoxystrobin was not significantly different from that in the nontreated plots $(39 \%$, TN-2009; $45 \%$, TN-2010; and $16 \%, \mathrm{RV}-2010)$. GSB severity in tebuconazole-treated plots $(27 \%$, TN-2009; 14\%, TN-2010; and 4\%, RV-2010) was significantly lower than all other treatments and the nontreated control. There was a consistent negative association between frequency of fungicide resistance and disease control in the field. Thus, knowledge of the frequency of fungicide resistance in the pathogen population will be helpful in selecting the most effective fungicides for the management of GSB in watermelon fields.
Gummy stem blight (GSB), caused by the fungus Didymella bryoniae (Fuckel) Rehm (anamorph Phoma cucurbitacearum (Fr.) Sacc.), is the most destructive disease of watermelon in greenhouses $(1,26)$ and in the major watermelon-producing areas of the southeastern United States $(22,24)$. The disease can spread rapidly and cause significant yield reductions in warm, wet conditions $(1,20)$. GSB can result in an average yield loss of $43 \%$ in nonsprayed plots $(7,9)$. Management of GSB requires an integration of both cultural practices and chemical methods; however, cultural practices such as deep turning of plant debris from the previous crop (6), crop rotation with a non-cucurbit host plant, incorporation of cabbage residue followed by soil solarization (5), and avoidance of overhead irrigation that favors the spread of the pathogen have limited effectiveness for GSB management. Genetic resistance to GSB has been identified recently in South Carolina (4) but GSBresistant watermelon cultivars are not yet commercially available. Frequent application of both protectant and systemic fungicides remains the most effective means of managing GSB. Unfortunately, $D$. bryoniae has shown a remarkable ability to adapt; resistance to effective systemic fungicides has become common within a few years of their introduction into management programs.

There are several examples of systemic fungicides that lost their effectiveness against GSB after only a few years of widespread use on watermelon. Thiophanate-methyl, a fungicide in the methyl benzimidazole carbamate fungicide class, provided good control of GSB until the early 1990s. A loss of efficacy was observed in the field and the resistance to thiophanate-methyl was confirmed in 1995 (9). In the late 1990s, the quinone-outside inhibitor (QoI) fungicide azoxystrobin provided excellent control of GSB (8) and

Corresponding author: K. L. Stevenson, E-mail: ks@uga.edu

Accepted for publication 30 June 2012.

http://dx.doi.org/10.1094/PDIS-02-12-0129-RE

(c) 2012 The American Phytopathological Society was granted section 18 Emergency Exemption in the 1998 growing season in Georgia to control GSB (24). However, within 2 years of the first commercial use of azoxystrobin, $D$. bryoniae isolates that were insensitive to azoxystrobin were found in Georgia, Delaware, and Maryland $(15,24)$. After development of resistance to azoxystrobin, a new fungicide, Pristine, which is a mixture of the QoI fungicide pyraclostrobin and boscalid, in the succinate dehydrogenase inhibitor (SDHI) class, showed good efficacy against GSB in the field (21). Isolates of $D$. bryoniae and other fungal pathogens that showed resistance against azoxystrobin were found to be sensitive to Pristine $(13,18)$. Pristine worked well against $D$. bryoniae until resistance to boscalid was observed in 2007 (23).

Demethylation-inhibiting (DMI) fungicides, introduced in the 1970s, have a broad spectrum of activity against different fungal pathogens and are used to manage a number of plant diseases (2). Although DMI fungicides have been widely used for managing a number of diseases, DMI fungicides have only recently been labeled for use on cucurbits (in 2008). Tebuconazole products (first labeled in 2008); Inspire Super, a formulated mixture of difenoconazole (DMI) and cyprodinil (anilinopyrimidine) (labeled in 2010); and Switch, a mixture of cyprodinil and fludioxanil (phenylpyrrole), are the only registered systemic fungicides against which no resistance has been reported in D. bryoniae. However, we have noticed a significant shift toward reduced sensitivity to tebuconazole in some field isolates collected from a commercial watermelon field in Florida in 2010 (unpublished data). Reduced sensitivity to DMI fungicides has been reported in many fungal pathogens $(3,11,14,17)$. Tebuconazole and difenoconazole belong to the same chemical group of triazoles within the DMI class and we have shown that there is potential for cross-resistance between these two fungicides based on a significant correlation between $50 \%$ effective concentration $\left(\mathrm{EC}_{50}\right)$ values of sensitive isolates (25).

With no GSB-resistant watermelon cultivars and limitations in effectiveness of cultural practices in the management of GSB, growers' reliance on the use of chemical fungicides is likely to continue. Therefore, it is essential that producers have a variety of chemical classes to use in rotation to avoid the build-up of re- 
sistance to individual fungicides, especially the DMIs. Commercial use of older fungicides thiophanate-methyl, azoxystrobin, and boscalid has decreased because of either reduced efficacy or the introduction of more efficacious systemic fungicides for the management of GSB. Unfortunately, threshold levels of frequency of resistance have not yet been established for individual fungicides to help decide whether to withdraw or continue using a fungicide once resistance has been reported. The objective of this study was to determine the relationship between the frequency of resistance to the fungicides boscalid, azoxystrobin, tebuconazole, difenoconazole, and thiophanate methyl and their efficacy in managing GSB.

\section{Materials and Methods}

Field experiments and fungicide treatments. Field experiments were conducted at the University of Georgia research farms in Tifton, GA in 2009 and 2010 and Reidsville, GA in 2010. Field location, year, watermelon cultivars, plot size, and spacing used for conducting the experiments are presented in Table 1. All experiments were arranged in a completely randomized block design with six treatments, including the untreated control, and five (Tifton) or six (Reidsville) replications. Approximately 4-week-old watermelon seedlings of a susceptible cultivar were transplanted onto raised beds covered with black polyethylene mulch. Treatments consisted of application of the following fungicides: boscalid (Endura $70 \mathrm{WG}, 0.474$ liters/ha), azoxystrobin (Quadris 2.08 SC, 0.906 liters/ha), tebuconazole (Folicur 3.6 SC, 0.585 liters/ha), thiophanate-methyl (Topsin 4.5 F, 0.731 liters/ha), and chlorothalonil (Bravo Weatherstik 6 SC, 2.34 liters/ha). Due to space limitations and because tebuconazole and difenoconazole share a common mode of action, only one of these (tebuconazole) was included as a treatment. Fungicides were applied using a Lee Spider Spray Trac sprayer with TX-18 hollow-cone nozzles calibrated to deliver 374 liters/ha at 517 to $552 \mathrm{kPa}$ to each treatment plot on a weekly basis following the recommended rates on the label, for a total of six applications per treatment. During the first year of the study, no measures were taken to prevent the movement of inoculum between plots except for the 4.5-m unplanted area between plots. In the second year of the study, in addition to the spacing between plots in the east-west direction, the plots were separated by two rows of sweet corn on the north and south sides of the plots to reduce interplot interference.

Watermelon leaves showing typical symptoms of GSB were collected from all plots except those treated with chlorothalonil. Leaves from untreated plots were collected midway through the season and leaves from treated plots were collected toward the end of the season, after all fungicides had been applied. A small section of infected tissue, approximately $0.09 \mathrm{~cm}^{2}$, was cut from the margin of one lesion on each leaf. The tissue pieces were surface disinfested with $0.6 \% \mathrm{NaOCl}$, rinsed in sterile water, and placed onto potato dextrose agar (PDA) amended with antibiotics (tetracycline, chloramphenicol, and streptomycin at $50 \mu \mathrm{g} / \mathrm{ml}$ each) and incubated at $25^{\circ} \mathrm{C}$ for 5 days. Fungal mycelium growing from the leaf tissue was transferred to PDA to obtain a pure culture. In all, 20 to 24 isolates of $D$. bryoniae were collected from each treatment (4 per replication) and tested for sensitivity to boscalid, tebuconazole, difenoconazole, thiophanate methyl, and azoxystrobin using an in vitro mycelial growth assay as described below. A discriminatory concentration of $3.0 \mu \mathrm{g} / \mathrm{ml}$ was used for boscalid (23), tebuconazole, and difenoconazole (25) and $100 \mu \mathrm{g} / \mathrm{ml}$ was used for thiophanate-methyl (9).

Fungicide sensitivity assays. Technical-grade boscalid $(98.4 \%$ a.i.; BASF Corporation), tebuconazole (97.5\% a.i.; Bayer Corpora- tion), and difenoconazole (95\% a.i.; Syngenta Crop Protection) were dissolved in acetone to obtain stock solutions of $30 \mathrm{mg} / \mathrm{ml}$. Serial dilutions of the stock solution of each fungicide were made in acetone and added to autoclaved PDA cooled to $55^{\circ} \mathrm{C}$ to obtain the desired concentration of $3.0 \mu \mathrm{g} / \mathrm{ml}$. The final concentration of acetone in fungicide-amended and nonamended medium (acetone only) was $0.1 \%$ by volume. Technical-grade thiophanate-methyl (95\% a.i.; United Phosphorus Inc.) was dissolved in dimethyl sulfoxide (DMSO) to make a stock solution of $10 \mathrm{mg} / \mathrm{ml}$. This stock solution $(10 \mathrm{ml})$ was added to autoclaved PDA cooled to $55^{\circ} \mathrm{C}$ to obtain the desired concentration of $100 \mu \mathrm{g} / \mathrm{ml}$. The final concentration of DMSO in fungicide-amended and nonamended medium (DMSO only) was $1.0 \%$ by volume.

Sensitivity of each isolate to tebuconazole, difenoconazole, boscalid, and thiophanate-methyl was determined using an in vitro mycelial growth assay on fungicide-amended and nonamended PDA. Mycelial plugs, $6 \mathrm{~mm}$ in diameter and taken from the margin of a 1-week-old pure culture on PDA, were placed upside down in the center of fungicide-amended and nonamended PDA plates. Two replications of each isolate and fungicide concentration were prepared. After 4 days of incubation in the dark at $25^{\circ} \mathrm{C}$, the diameter of each colony was measured and corrected by subtracting the diameter of the mycelial plug. Relative growth was calculated as the corrected colony diameter on fungicide-amended medium divided by the corrected colony diameter on nonamended medium. Isolates with a relative growth value greater than 0.25 on fungicide-amended medium were considered resistant to the respective fungicides.

Sensitivity to azoxystrobin. Technical-grade azoxystrobin (Syngenta Crop Protection) was dissolved in acetone to make a stock solution of $10 \mathrm{mg} / \mathrm{ml}$. An aliquant of stock solution was added to autoclaved water agar cooled to $55^{\circ} \mathrm{C}$ to obtain a final azoxystrobin concentration of $10 \mu \mathrm{g} / \mathrm{ml}$. The concentration of acetone was $0.1 \%$ in both fungicide-amended and nonamended medium. Medium with and without fungicide was also amended with salicylhydroxamic acid at $100 \mu \mathrm{g} / \mathrm{ml}$ to inhibit the alternative respiratory pathway in the fungus that can affect the activity of the fungicide (16).

Sensitivity to azoxystrobin was tested using a spore germination assay. Isolates of $D$. bryoniae were grown on quarter-strength PDA for 2 weeks at $25^{\circ} \mathrm{C}$ under a photoperiod of $12 \mathrm{~h}$ of darkness and $12 \mathrm{~h}$ of light to induce sporulation. Conidial suspensions of each isolate were prepared by flooding the plates with $2 \mathrm{ml}$ of a solution of sterile water and Tween 20 ( 1 drop of Tween per $100 \mathrm{ml}$ of water) and gently scraping the surface of the mycelia with a glass rod to dislodge the conidia. Conidial suspension (10 to $15 \mu \mathrm{l}$ ) from each individual isolate was transferred and spread out onto fungicide-amended and nonamended plates. Two replicate plates of each isolate and treatment combination were prepared. After incubating at $25^{\circ} \mathrm{C}$ for $24 \mathrm{~h}, 50$ spores per plate were examined microscopically and the percentage of germination was recorded. A conidium was considered germinated if the length of the germ tube was at least half the length of the conidium. Relative germination was calculated as the percent germination on fungicide-amended medium divided by the percent germination on nonamended medium. An isolate was considered resistant if the relative germination on fungicide-amended medium was greater than 0.5 (25).

Statistical analysis. Disease severity expressed as the percentage of diseased leaf area in each plot was assessed visually on a weekly basis for 3 to 5 weeks after symptoms of GSB were first observed. Fewer assessments were made when disease pressure was low (Reidsville), when heavy defoliation from downy mildew

Table 1. Year, field location, watermelon cultivar, plot size, and plant spacing used for evaluation of efficacy of fungicides for management of gummy stem blight under field conditions

\begin{tabular}{lllcc}
\hline Year & Location & Cultivar & Plot size (m) & Plant spacing (m) \\
\hline 2009 & Tifton & Summer Flavor 800 & $1.8 \times 6$ & $1.8 \times 0.6$ \\
2010 & Reidsville & Crimson sweet & $5.4 \times 7.5$ & $1.8 \times 0.9$ \\
2010 & Tifton & Crimson sweet & $9 \times 7.5$ & $1.8 \times 1.2$ \\
\hline
\end{tabular}


occurred (Tifton, 2010), or as the result of early decline of vines when the experiment was conducted in fall rather than summer. The area under the disease progress curve (AUDPC) was calculated for each plot. Data were analyzed using PROC MIXED of SAS (version 9.2; SAS Institute Inc.), with fungicide treatment included as a fixed effect and block as a random effect in the model. Least squares means were compared using the PDIFF option in SAS.

\section{Results}

GSB was severe in Tifton in fall 2009 and 2010 and was considerably less severe in Reidsville in fall 2010. In Tifton in 2009, symptoms of GSB were first observed 2 weeks after transplanting and disease progressed rapidly and resulted in nearly complete defoliation in the nontreated control plots within 6 weeks after first appearance of symptoms (Fig. 1). In 2010, in Reidsville, the onset of disease was delayed when compared with Tifton plots and disease development was slower (Fig. 2). This might have been due to the dry weather that lasted throughout the growing season in Reidsville. An adjacent muskmelon field that was heavily infected with GSB may have served as a source of inoculum that contributed to the early onset and severe epidemic of GSB in Tifton in 2010. Downy mildew, caused by Pseudoperonospora cubensis, contributed to severe necrotic symptoms similar to those caused by D. bryoniae and caused heavy defoliation in both treated and nontreated plots in 2010 in both Tifton and Reidsville. Experimental plots in Tifton were more severely affected by downy mildew when compared with Reidsville.

Maximum disease severity and AUDPC values were significantly lower in tebuconazole- and chlorothalonil-treated plots when compared with all other treatments in both 2009 and 2010 in both experimental sites (Table 2). Maximum disease severity in all other treatments was comparable with that of nontreated plots, except for the azoxystrobin treatment in Reidsville in 2010. Maximum disease severity was significantly higher in azoxystrobin-treated plots when compared with all other treatments (Table 2). AUDPC values were significantly higher for azoxystrobin-treated plots in Tifton and Reidsville in 2009 and 2010 and also for thiophanate-methyl-treated plots in Tifton in 2010 when compared with the nontreated control (Table 2).

All isolates collected from both experimental sites in both years were sensitive to tebuconazole and difenoconazole (Table 2). Frequency of resistance to boscalid, azoxystrobin, and thiophanatemethyl in isolates collected from nontreated plots, representing the initial population, was $80 \%$ or higher in both locations and years (Table 2). All isolates collected at the end of the season after exposure to six fungicide applications were resistant to these fungicides (Table 2). In 2009, in Tifton, the frequency of resistance to bos-

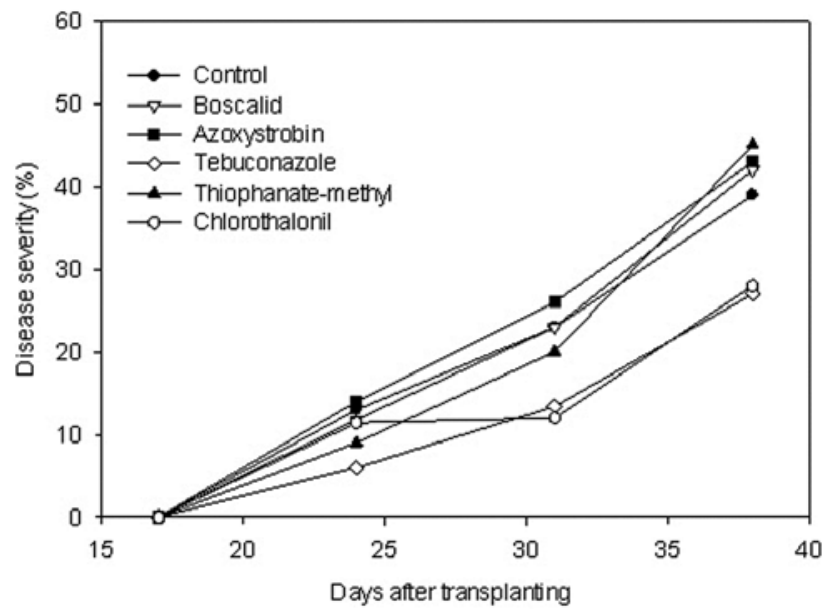

Fig. 1. Effect of weekly fungicide applications on progress of gummy stem blight epidemics, caused by Didymella bryoniae, in field experiments conducted in fall 2009 in Tifton, GA. calid was significantly lower in thiophanate-methyl-treated plots when compared with all other treatments. Frequency of resistance to the other fungicides was not significantly affected by the treatments in Tifton. In 2010, frequency of resistance to boscalid was significantly lower in tebuconazole-treated plots when compared with boscalid treatment in Tifton but was not significantly different from the nontreated controls (Table 2). Frequency of resistance to boscalid was significantly lower in tebuconazole-treated plots when compared with boscalid and thiophanate-methyl-treated plots in Reidsville but was not significantly different from the nontreated control. Frequency of resistance to the other fungicides was not significantly affected by any of the treatments in Reidsville and Tifton (Table 2).

\section{Discussion}

Chlorothalonil and tebuconazole provided superior disease suppression when compared with all other fungicide treatments in both years and locations. These results are in agreement with a previous report on the effectiveness of chlorothalonil and DMIs in managing GSB (19). These fungicides were effective in managing GSB regardless of the amount of disease pressure or the time of onset of disease. Growers may choose to apply chlorothalonil up until 21 days before harvest because of its efficacy and to reduce pathogen exposure to fungicides with a higher risk of resistance development. However, chlorothalonil can cause phytotoxicity on mature watermelon rinds and, for this reason, growers tend to avoid using chlorothalonil products late in the season (24). Tebuconazole can be used as an alternative to chlorothalonil and provides a good rotation partner with QoI and SDHI fungicides. QoIs and SDHIs should be used sparingly during the season to reduce selection of resistant isolates. In most cases, QoIs and SDHIs can be eliminated altogether for controlling GSB, with the exception of the SDHI fluopyram, to which no cross-resistance to other SDHIs has been reported.

This study was aimed at establishing the relationship between frequency of fungicide resistance in D. bryoniae based on in vitro

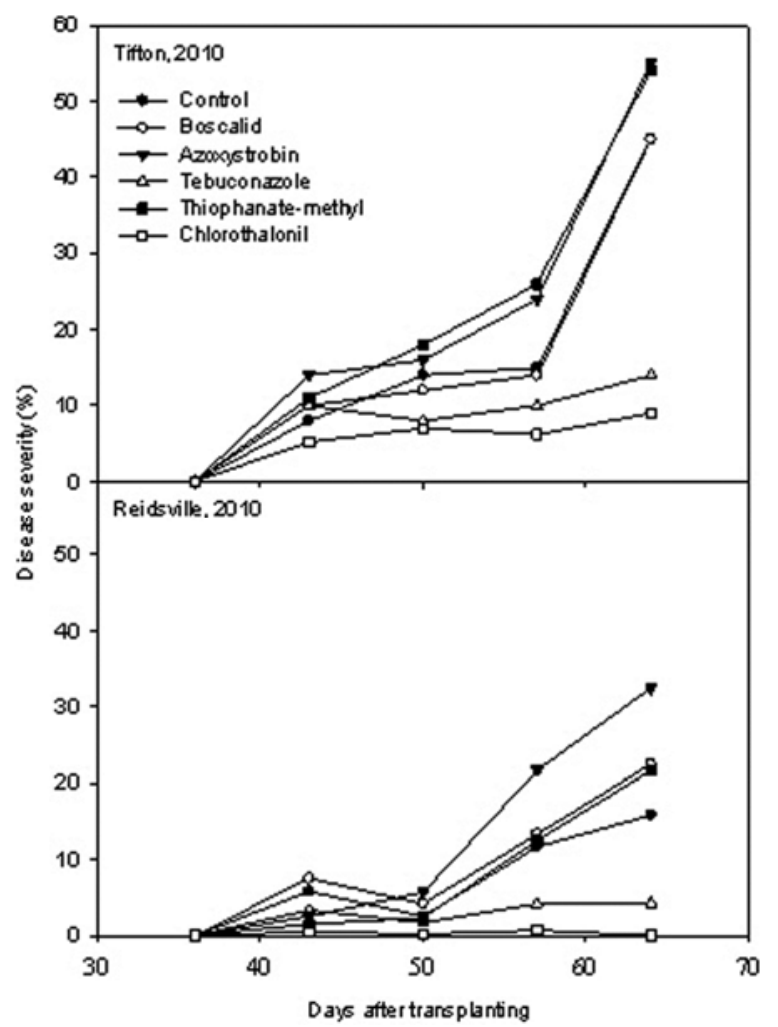

Fig. 2. Effect of weekly fungicide applications on progress of gummy stem blight epidemics, caused by Didymella bryoniae, in field experiments conducted in fall 2010 in Tifton and Reidsville, GA. 
assays and fungicide efficacy for GSB management in watermelon fields. With the development of resistance to all systemic fungicides that were once effective, watermelon growers in Georgia are currently relying heavily on DMI fungicides for managing GSB. Therefore, it is very important to monitor and manage the development of resistance to these DMI fungicides because this is the only group of effective systemic fungicides that is available to the growers in Georgia. Lack of new systemic fungicides with different modes of action motivated us to consider older systemic fungicides as potential rotation partners. Because the initial population was already highly resistant to these fungicides, it was not possible to determine the threshold for frequency of resistance below which the fungicide would still be effective in managing GSB. The only inference with respect to the relationship between frequency of resistance and fungicide efficacy that can be drawn from this study is that there is a negative relationship between frequency of resistance and fungicide efficacy; the higher the frequency of resistance to an individual fungicide, the lower the efficacy in managing GSB. From this study it is clear that if the frequency of resistance is more than $0.9,0.95$, and 0.80 to boscalid, azoxystrobin, and thiophanate-methyl, respectively, in the initial population, then these fungicides are likely to be ineffective against GSB. Because the range of resistance frequencies was limited in these studies, the minimum frequencies of resistance that are likely to result in control failure remain unknown but may be considerably lower.

In field experiments conducted in Tifton and Reidsville in 2009 and 2010, the frequency of resistance to boscalid, azoxystrobin, and thiophanate-methyl was 0.80 or higher among the isolates collected from nontreated plots, indicating that the initial population was already highly resistant to these fungicides. The relative epidemiological importance of different sources of initial inoculum for GSB epidemics is not very well understood; therefore, we can only speculate as to the origin of these highly resistant populations. Reported sources of initial inoculum include ascospores produced on watermelon debris from the previous season $(20,26)$. However, GSB was very severe in Georgia from 2008 to 2010 even though very few ascospores were detected in watermelon production fields prior to epidemic onset (unpublished data). The disease can also be initiated by splash-dispersed conidia produced in pycnidia formed on watermelon debris from the previous season (6). It has also been shown that GSB can be seedborne (12). The widespread resistance to systemic fungicides points to ascospores or infested seed as the primary sources of inoculum. However, failure to detect ascospores in Georgia prior to disease outbreaks does not support the hypothesis of ascospores as the primary source of inoculum. Reports of GSB in transplant production greenhouses suggest that infested seed may serve as the primary source $(10,24)$ for fungicide-resistant inoculum. Currently, no systemic fungicides are labeled for use in transplant production houses. However, the possibility of off-label use of systemic fungicides in transplant production houses, although unlikely, could select for resistant isolates on transplants that serve as a source of fungicide-resistant inoculum in the field. A detailed study of the role of ascospores, conidia, and infested seed as primary sources of inoculum is needed to explain the origin of fungicide-resistant inoculum.

In this study, it was observed that treatment with azoxystrobin consistently exacerbated GSB, resulting in significantly higher AUDPC compared with nontreated plots in two of the three experiments. This increased disease development could be because of the competitive advantage of resistant isolates in the presence of azoxystrobin. However, a detailed comparative study of the relative fitness of azoxystrobin-resistant and azoxystrobin-sensitive isolates is needed before drawing further conclusions. Another possible explanation for the poor performance of azoxystrobin could be that its broad spectrum of activity may have inhibited beneficial microorganisms that are antagonists of $D$. bryoniae, thus providing a better environment for azoxystrobin-resistant isolates to survive.

An interesting outcome of this study is that tebuconazole treatment may have an effect on isolates resistant to boscalid. In Reidsville in 2010, the frequency of resistance to boscalid was significantly lower in the tebuconazole-treated plots compared with those treated with boscalid or thiophanate-methyl, even though the frequency of resistance to boscalid in these treatments was not significantly different from the nontreated control. In Tifton in 2010, tebuconazole treatment also resulted in a significantly lower

Table 2. Effects of weekly fungicide treatments on gummy stem blight epidemics and frequency of resistance to fungicides in Didymella byroniae recovered from diseased watermelon plants ${ }^{\mathrm{v}}$

\begin{tabular}{|c|c|c|c|c|c|c|c|}
\hline \multirow[b]{2}{*}{ Location, year, treatment } & \multirow[b]{2}{*}{ Disease $(\%)^{x}$} & \multirow[b]{2}{*}{ AUDPC $^{\mathbf{y}}$} & \multicolumn{5}{|c|}{ Frequency of resistance to ${ }^{w}$} \\
\hline & & & BOS & AZO & TPM & TEB & DIF \\
\hline \multicolumn{8}{|l|}{ Tifton, 2009 } \\
\hline Nontreated & $39.0 \mathrm{abc}$ & $388.5 \mathrm{a}-\mathrm{d}$ & $1.00 \mathrm{a}$ & $1.00 \mathrm{a}$ & $0.80 \mathrm{a}$ & $0.00 \mathrm{a}$ & $0.00 \mathrm{a}$ \\
\hline Chlorothalonil & $28.0 \mathrm{def}$ & $261.8 \mathrm{fg}$ & & & & & \\
\hline Boscalid & $42.0 \mathrm{abc}$ & $390.5 \mathrm{a}-\mathrm{d}$ & $1.00 \mathrm{a}$ & $1.00 \mathrm{a}$ & $0.75 \mathrm{a}$ & $0.00 \mathrm{a}$ & $0.00 \mathrm{a}$ \\
\hline Azoxystrobin & $43.0 \mathrm{ab}$ & $430.5 \mathrm{ab}$ & $1.00 \mathrm{a}$ & $1.00 \mathrm{a}$ & $0.88 \mathrm{a}$ & $0.00 \mathrm{a}$ & $0.00 \mathrm{a}$ \\
\hline Thiophanate-methyl & $45.0 \mathrm{a}$ & $360.5 \mathrm{~cd}$ & $0.80 \mathrm{~b}$ & $1.00 \mathrm{a}$ & $1.00 \mathrm{a}$ & $0.00 \mathrm{a}$ & $0.00 \mathrm{a}$ \\
\hline Tebuconazole & $27.0 \mathrm{ef}$ & $230.3 \mathrm{~g}$ & $1.00 \mathrm{a}$ & $1.00 \mathrm{a}$ & $0.90 \mathrm{a}$ & $0.00 \mathrm{a}$ & $0.00 \mathrm{a}$ \\
\hline \multicolumn{8}{|l|}{ Tifton, 2010} \\
\hline Nontreated & $45.0 \mathrm{a}$ & $399.0 \mathrm{~b}$ & $0.90 \mathrm{ab}$ & $0.98 \mathrm{a}$ & $0.94 \mathrm{a}$ & $0.00 \mathrm{a}$ & $0.00 \mathrm{a}$ \\
\hline Chlorothalonil & $9.0 \mathrm{~b}$ & $142.1 \mathrm{c}$ & $\ldots$ & $\ldots$ & $\ldots$ & $\ldots$ & $\ldots$ \\
\hline Boscalid & $45.0 \mathrm{a}$ & $374.5 \mathrm{~b}$ & $1.00 \mathrm{a}$ & $1.00 \mathrm{a}$ & $0.90 \mathrm{a}$ & $0.00 \mathrm{a}$ & $0.00 \mathrm{a}$ \\
\hline Azoxystrobin & $55.0 \mathrm{a}$ & $521.5 \mathrm{a}$ & $0.95 \mathrm{ab}$ & $1.00 \mathrm{a}$ & $0.95 \mathrm{a}$ & $0.00 \mathrm{a}$ & $0.00 \mathrm{a}$ \\
\hline Thiophanate-methyl & $54.0 \mathrm{a}$ & $535.5 \mathrm{a}$ & $0.90 \mathrm{ab}$ & $1.00 \mathrm{a}$ & $1.00 \mathrm{a}$ & $0.00 \mathrm{a}$ & $0.00 \mathrm{a}$ \\
\hline Tebuconazole & $14.0 \mathrm{~b}$ & $210.0 \mathrm{c}$ & $0.85 \mathrm{~b}$ & $0.95 \mathrm{a}$ & $0.90 \mathrm{a}$ & $0.00 \mathrm{a}$ & $0.00 \mathrm{a}$ \\
\hline \multicolumn{8}{|l|}{ Reidsville, 2010} \\
\hline Nontreated & $15.8 \mathrm{~b}$ & $175.0 \mathrm{~b}$ & $0.93 \mathrm{ab}$ & $0.95 \mathrm{a}$ & $0.97 \mathrm{a}$ & $0.00 \mathrm{a}$ & $0.00 \mathrm{a}$ \\
\hline Chlorothalonil & $1.0 \mathrm{c}$ & $7.6 \mathrm{c}$ & $\ldots$ & $\ldots$ & $\ldots$ & $\ldots$ & $\ldots$ \\
\hline Boscalid & $22.5 \mathrm{~b}$ & $227.5 \mathrm{~b}$ & $1.00 \mathrm{a}$ & $0.83 \mathrm{a}$ & $0.79 \mathrm{a}$ & $0.00 \mathrm{a}$ & $0.00 \mathrm{a}$ \\
\hline Azoxystrobin & $32.5 \mathrm{a}$ & $313.7 \mathrm{a}$ & $0.95 \mathrm{ab}$ & $1.00 \mathrm{a}$ & $1.00 \mathrm{a}$ & $0.00 \mathrm{a}$ & $0.00 \mathrm{a}$ \\
\hline Thiophanate-methyl & $21.7 \mathrm{~b}$ & $184.9 \mathrm{~b}$ & $1.00 \mathrm{a}$ & $1.00 \mathrm{a}$ & $1.00 \mathrm{a}$ & $0.00 \mathrm{a}$ & $0.00 \mathrm{a}$ \\
\hline Tebuconazole & $4.2 \mathrm{c}$ & $67.1 \mathrm{c}$ & $0.72 \mathrm{~b}$ & $0.70 \mathrm{a}$ & $0.83 \mathrm{a}$ & $0.00 \mathrm{a}$ & $0.00 \mathrm{a}$ \\
\hline
\end{tabular}

${ }^{\mathrm{v}}$ Within each location and year, values within a column followed by the same letter are not significantly different based on comparison of least squares means $(\alpha=0.05)$.

${ }^{\mathrm{w}}$ Frequency of resistance $=($ number of isolates resistant to a fungicide $) /($ total number of isolates collected from each treatment $) . \mathrm{BOS}=$ boscalid, $\mathrm{AZO}=$ azoxystrobin, TPM = thiophanate-methyl, TEB = tebuconazole, and DIF = difenoconazole. Frequency of resistance to chlorothalonil was not determined.

${ }^{\mathrm{x}}$ Maximum disease severity.

y Area under the disease progress curve.

${ }^{\mathrm{z}}$ Results shown for Tifton 2009 are part of a larger field experiment. Only data from treatments of interest are shown here. 
frequency of resistance to boscalid compared with plots treated with boscalid, although the frequency of resistance to boscalid was not significantly different from the nontreated control. A similar trend was observed for azoxystrobin resistance in tebuconazoletreated plots in Reidsville but the difference in frequency was not statistically significant. However, because disease incidence was generally low in tebuconazole-treated plots, only one isolate was obtained from each of two of the replicate plots and both isolates were resistant to azoxystrobin. This may have contributed to the increased variation among replications and failure to detect significant differences among treatments in that experiment. Further analysis revealed that the tebuconazole treatment significantly reduced the frequency of resistance to azoxystrobin when data from these two plots with one isolate each were omitted from the data set.

Another interesting observation from this study is that the frequency of resistance to thiophanate-methyl was generally lower than expected across all treatments. Thiophanate-methyl has not been used routinely for managing GSB in recent years because of resistance to this product and because of the availability of alternative fungicides (e.g., boscalid, azoxystrobin, and chlorothalonil). This prolonged period of disuse may have enabled the build-up of thiophanate-methyl-sensitive isolates of $D$. bryoniae. All isolates were sensitive to tebuconazole and difenoconazole, based on lack of growth on medium amended with tebuconazole or difenoconazole at $3.0 \mu \mathrm{g} / \mathrm{ml}$. However, there may be a small but significant difference in sensitivity to tebuconazole between isolates that are resistant to boscalid or azoxystrobin and those that are sensitive to boscalid or azoxystrobin that was not evident based on growth on a single high concentration of tebuconazole. A fitness cost associated with resistance to boscalid that gives boscalid-sensitive isolates a competitive advantage over resistant isolates when exposed to tebuconazole could also account for the lower frequency of resistance to boscalid among isolates from tebuconazole-treated plants. This result is particularly important in light of the high level of resistance to boscalid in Georgia and other watermelon-producing states in the eastern United States. Based on these results, exposure to chemically unrelated fungicides may have unexpected impacts on the frequency of resistance in the pathogen population that deserve further investigation.

\section{Literature Cited}

1. Arny, C. J., and Rowe, R. C. 1991. Effects of temperature and duration of surface wetness on spore production and infection of cucumbers by Didymella bryoniae. Phytopathology 81:206-209.

2. Brent, K. J., and Hollomon, D. W. 2007. Fungicide resistance in crop pathogens: how can it be managed? Fungicide Resistance Action Committee Monogr. No. 1

3. Délye, C., Laigret, F., and Corio-Costef, M. F. 1997. A mutation in the 14 alpha demethylase gene of Uncinula necator that correlates with resistance to a sterol biosynthesis inhibitor. Appl. Environ. Microbiol. 63:2966-2970.

4. Gusumini, G., Song, R., and Wehner, T. C. 2005. New sources of resistance to gummy stem blight in watermelon. Crop Sci. 45:582-588

5. Keinath, A. P. 1996. Soil amendment with cabbage residue and crop rotation to reduce gummy stem blight and increase growth and yield of watermelon. Plant Dis. 80:564-570.
6. Keinath, A. P. 2002. Survival of Didymella bryoniae in buried watermelon vines in South Carolina. Plant Dis. 86:32-38.

7. Keinath, A. P., and Duthie, J. A. 1998. Yield and quality reduction in watermelon due to anthracnose, gummy stem blight and black rot. Pages 77-90 in: Recent Research Developments in Plant Pathology, Vol. 2. Research Signpost, Trivandrum, India.

8. Keinath, A. P., May, W., III, and Du Bose, V. 1999. Effects of number of sequential Quadris applications and companion fungicide on foliar disease of watermelon, 1998. Fungic. Nematicide Tests 54:279.

9. Keinath, A. P., and Zitter, T. A. 1998. Resistance to benomyl and thiophanate-methyl in Didymella bryoniae from South Carolina and New York. Plant Dis. 82:479-484.

10. Koike, S. T. 1997. First report of gummy stem blight, caused by Didymella bryoniae, on watermelon transplants in California. Plant Dis. 81:1331.

11. Köller, W., Wilcox, W. F., Barnard, T., Jones, A. L., and Braun, G. 1997. Detection and quantification of resistance of Venturia inaequalis populations to sterol demethylation inhibitors. Phytopathology 87:184-190.

12. Lee, D. H., Mathur, S. B., and Neergard, P. 1984. Detection and location of seed-borne inoculum of Didymella bryoniae and its transmission in seedlings of cucumber and pumpkin. Phytopathol. Z. 109:301-308.

13. Markoglou, A., Malandrakin, A., Vitoratos, A., and Ziogas, B. 2006. Characterization of laboratory mutants of Botrytis cinerea resistant to QoI fungicides. Eur. J. Plant Pathol. 115:149-162.

14. Mavroeidi, V. I., and Shaw, M. W. 2005. Sensitivity distributions and crossresistance patterns of Mycosphaerella graminicola to fluquinconazole, prochloraz and azoxystrobin over a period of 9 years. Crop Prot. 24:259-266.

15. Olaya, G., and Holm, A. 2001. Sensitivity of Didymella bryoniae isolates to azoxystrobin. (Abstr.) Phytopathology 91:S67.

16. Olaya, G., and Köller, W. 1999. Baseline sensitivities of Venturia inaequalis populations to strobilurin fungicide kresoxim-methyl. Plant Dis. 83:274278.

17. Parker, D. M., Zhang, N., Smart, C. D., and Köller, W. D. 2006. Polymorphism of 14 alpha-demethylase gene (CYP51) in brown rot pathogen Monilinia fructicola from a resistant orchard in New York State. (Abstr.) Phytopathology 96:S90.

18. Pasche, J. S., Piche, L. M., and Gudmestad, N. C. 2005. Effect of the F129L mutation in Alternaria solani on fungicides affecting mitochondrial respiration. Plant Dis. 89:269-278.

19. Sanders, F. H., Jr., and Langston, D. B., Jr. 2009. Evaluation of fungicide sprays on gummy stem blight of watermelon in Georgia I, 2009. Plant Dis. Manage. Rep. 4, Vol. 152:1

20. Schenck, N. C. 1968. Epidemiology of gummy stem blight (Mycosphaerella citrullina) on watermelon: Ascospore incidence and disease development. Phytopathology 58:1420-1422.

21. Seebold, K., and Langston, D. B., Jr. 2004. Evaluation of fungicides for control of gummy stem blight of watermelon. Fungic. Nematicide Tests 59:140.

22. Sitterly, W. R., and Keinath, A. P. 1996. Gummy stem blight. Pages 27-28 in: Compendium of Cucurbit Diseases. T. A. Zitter, D. L. Hopkins, and C. E. Thomas, eds. American Phytopathological Society, St. Paul, MN

23. Stevenson, K. L., Langston, D. B., Jr., and Sanders, F. 2008. Baseline sensitivity and evidence of resistance to boscalid in Didymella bryoniae. (Abstr.) Phytopathology 98:S151.

24. Stevenson, K. L., Langston, D. B., Jr., and Seebold, K. W. 2004. Resistance to azoxystrobin in the gummy stem blight pathogen documented in Georgia Plant Health Progress. Online publication. doi:10.1094/PHP-2004-1207-01RS

25. Thomas, A., Langston, D. B., Jr., and Stevenson, K. L. 2012. Baseline sensitivity and cross-resistance to succinate-debydrogenase-inhibiting and demethylation-inhibiting fungicides in Didymella bryoniae. Plant Dis. 96:979-984.

26. Van Steekelenburg, N. A. M. 1983. Epidemiological aspects of Didymella bryoniae, the cause of stem and fruit rot of cucumber. Neth. J. Plant Pathol. 89:75-86. 